This is the author's copy of a paper accepted for publication in the International Journal of Fatigue (http://dx.doi.org/10.1016/j.ijfatigue.2014.04.003)

\title{
A quantitative three-dimensional in situ study of a short fatigue crack in a magnesium alloy
}

T. J. Marrow ${ }^{1}$, M. Mostafavi², T. Hashimoto ${ }^{3}$ and G. E. Thompson ${ }^{3}$

1 Department of Materials, Oxford University, Parks Rd, Oxford, OX1 3PH, UK, james.marrow@materials.ox.ac.uk

${ }^{2}$ Department of Mechanical Engineering, University of Sheffield, Mappin Street, Sheffield, S1 3JD, UK, m.mostafavi@sheffield.ac.uk

${ }^{3}$ School of Materials, The University of Manchester, Manchester, M13 9PL, UK, t.hashimoto@manchester.ac.uk, george.thompson@manchester.ac.uk

* Corresponding author: james.marrow@materials.ox.ac.uk, tel: +44 (0) 1865 273938

\section{Highlights}

- Destructive 3D analysis is compared with non-destructive X-ray Computed Micro-Tomography.

- Serial Block Face Scanning Electron Microscopy of a fatigue crack in magnesium has been done.

- Three-dimensional fractography reveals the microstructure influence on crack propagation.

- Digital volume correlation measures the crack opening displacements and opening modes in 3D.

- Twinning deflects the crack path and retards the crack propagation rate.

\section{Abstract}

A previous four-dimensional in situ study of a short crack in a magnesium alloy [14], Elektron 21, used synchrotron X-ray computed micro-tomography to follow its three-dimensional development with progressive fatigue cycling through the microstructure, which had been mapped by diffraction contrast tomography to measure grain shapes and crystal orientations in three dimensions. In the present work, very high-resolution post-test examination of the same sample by Serial Block Face Scanning Electron Microscopy (SBFSEM) provided threedimensional fractographs to investigate the influence of microstructural features on the measured crack propagation rates. Digital volume correlation, applied to the X-ray computed micro-tomography datasets, measured the threedimensional crack opening displacements and hence the crack opening modes. 
This is the author's copy of a paper accepted for publication in the International Journal of Fatigue (http://dx.doi.org/10.1016/j.ijfatigue.2014.04.003)

The short fatigue crack in magnesium propagated with mixed mode opening. Basal plane fracture is a dominant mechanism; hence, boundaries that disrupt the continuity of the basal plane are proposed to influence the crack propagation rate.

\section{Keywords}

Fatigue; X-Ray Computed Micro-tomography; Digital Volume Correlation; Serial Sectioning; Crack Opening Displacement; Twinning

\section{Introduction}

Cracks have three-dimensional (3D) geometries; they also interact with the three-dimensional microstructure of the material as they develop. These interactions are particularly important for microstructural short cracks, which are short relative to microstructure length scales, such as grain size, since the crystallographic orientations of the grains can strongly affect stage I cracks that follow particular crystallographic slip planes [1]. The fatigue lifetime of engineering components can be dominated by the short crack regime; hence, understanding of short crack behaviour is quite important. However, the short crack regime represents a field of experimental study and modelling of 3D crack behaviour that is most difficult, with detailed understanding and data most limited despite significant developments in recent decades (e.g. [2], [3]). A key goal of research into short fatigue cracks is predicting the probability of crack growth to a critical size within a given interval of life. The intrinsic material factors on which this depends include crystallographic texture, grain shape and size. In order to implement these in predictive models such as [3], knowledge is required of crack growth rates within grains and the resistance to crack growth presented by features such as grain boundaries.

Three-dimensional in situ observation of crack development within materials has become possible with the wider availability of high-resolution X-ray computed micro-tomography ( $\mu \mathrm{XCT}$ ) [4]-[9], aided particularly by the brilliance of synchrotron sources that allow sequential observations in a reasonable time. Recently, non-destructive 3D grain mapping techniques such as synchrotron Xray diffraction contrast tomography (DCT) have complemented $\mu \mathrm{XCT}$ by providing a description of grain shape and crystal orientation in polycrystalline materials [10]. DCT, which maps the microstructure by reconstructive analysis of the diffraction spots from individual grains, has been used to characterise the microstructure prior to crack development, showing, for the first time, the interaction of cracks with grains and grain boundaries [11]-[13]. In one recent study [14], short fatigue crack growth behaviour in a cast magnesium alloy (Elektron 21) was observed in 3D using a combination of DCT and $\mu$ XCT at the European Synchrotron Radiation Facility (ESRF). The evolution of a fatigue crack from an artificial notch, smaller than one grain, was studied in situ during interrupted fatigue cycling. Crack growth occurred preferentially on the basal plane of the magnesium hexagonal close packed crystal, with local crack growth rates varying between 4 and $40 \mathrm{~nm} /$ cycle. By combining DCT and $\mu \mathrm{XCT}$, it was 
This is the author's copy of a paper accepted for publication in the International Journal of Fatigue (http://dx.doi.org/10.1016/j.ijfatigue.2014.04.003)

possible to relate the orientation of the local crack plane to the grain orientations and, hence, to the crack propagation behaviour. Higher crack growth rates were associated with basal plane propagation and lower rates tended to be associated with non-crystallographically oriented regions of the crack. Crystallographic crack propagation was observed to be retarded at boundaries with large tilt/twist misorientations of the basal slip plane. However, the resolution of the $\mu \mathrm{XCT}$ observations was insufficient to discern the fine topography of crack propagation (i.e. fractography); this could have determined, for instance, whether the crystallographic to non-crystallographic transition was associated with a change from a flat topography to the "staircase" morphology of alternating propagation planes [15].

The Schmid factor is a fundamental element in models that are used to interpret observations of crystal deformation and also in predictive models for fatigue initiation and propagation; it is a measure of the resolved shear stress on the slip systems of a grain. Crystallographic fatigue crack growth is observed to occur along slip planes of high Schmid factor [16], and models for fatigue assume such cracking to be driven by the shear modes of deformation [17]. The transition from crystallographic to non-crystallographic fatigue crack propagation is considered to be accompanied by a transition from shear to tensile modes of crack opening (i.e. mode II to mode I) as multiple slip systems are activated [18]. In simpler fatigue models, the Schmid factor may be estimated with an assumption of uniaxial tension ([19], [20]), whilst more sophisticated crystal plasticity models consider the local stresses and strains from three-dimensional grain interactions ([3], [21]). In the case of crack propagation, the geometry and orientation of the three-dimensional crack must also be taken into account [22]. These define the local magnitudes and modes of the crack opening displacements that, to our knowledge, have never been measured, at least in three dimensions, for a short fatigue crack. Since the above-mentioned study on Elektron 21 was conducted, two novel techniques have become available that can provide the necessary insight into the fractography and opening modes of three-dimensional cracks: these are (i) very high resolution, large volume ultramicrotomy with low-voltage scanning electron microscopy, and (ii) digital volume correlation of $\mu$ XCT datasets.

Destructive, i.e. post-test, techniques of serial sectioning that typically use focused ion beams to reconstruct the microstructure with very high resolution have had limited application in studies of short fatigue cracks [23] since the sectioning of the large volumes required to observe the crack in sufficient grains can be prohibitive. Conversely, although X-ray tomography allows the study of larger volumes, its resolution (typically sub-micron) is generally insufficient for the 3D fractographic characterisation of crack propagation, which is necessary to determine the crack propagation mode with confidence; useful observations have been achieved, though, when the fracture surface roughness is significant [9]. The new destructive technique of ultramicrotomy by Serial Block Face Scanning Electron Microscopy (SBFSEM) [24] allows larger volumes to be studied with very high resolutions achievable by scanning electron microscopy. Although such post-test methods can only investigate damaged and deformed 
This is the author's copy of a paper accepted for publication in the International Journal of Fatigue (http://dx.doi.org/10.1016/j.ijfatigue.2014.04.003)

microstructures, thereby losing the damage chronology afforded by $\mu \mathrm{XCT}$, they may complement lower resolution in situ studies.

Previous X-ray tomography studies have been largely qualitative, taking advantage of 3D visualisation to measure crack morphology and dimensions (e.g. [6]-[8]). Quantitative measurements can be obtained now by digital volume correlation (DVC), which is a powerful analysis technique applied to sequential three-dimensional observations to map the relative changes in displacement with sub-voxel resolution [25]. With increases in computational power, DVC can be readily applied to the large datasets produced by high-resolution X-ray tomography. Often applied in studies of bulk deformation and plasticity [26][29], it can yield particularly useful insights into crack development by allowing precise measurement of crack opening displacements and modes of loading [31][33].

In this paper, we have returned to the magnesium fatigue sample and X-ray micro-tomography data of the previous experiment [14] in order to investigate the fractography of crack propagation by SBFSEM of the sample and also to measure the modes and magnitude of the crack opening displacements by DVC. Our goal is to demonstrate the additional insights that can be obtained which, in future work, might be used to validate advanced crystal plasticity models for short fatigue crack propagation and the fatigue lifetime prediction of engineering components.

\section{Methods and Materials}

\subsection{In situ observation of fatigue crack propagation by X-ray microtomography $(\mu \mathrm{XCT})$}

A full description of the fatigue experiment has been provided in the previous publication [14]; the relevant details are reported here briefly. The material was an annealed Elektron 21 magnesium alloy (a casting alloy containing nominally 2.6-3.1\% neodymium, $1.0-1.7 \%$ gadolinium and $0.2-0.5 \%$ zinc), with a grain size of approximately $55 \mu \mathrm{m}$. Following DCT characterization of the tensile fatigue specimen (1 mm gauge diameter), a focused ion beam (FIB) instrument was used to introduce sharp notches in selected grains.

The sample was fatigue tested with a sinusoidal waveform at a frequency of $5 \mathrm{~Hz}$ with a maximum stress of $130 \mathrm{MPa}$ and R-ratio (minimum/maximum load) of 0.25. The cycling was interrupted at intervals for tomographic scanning from 500 to 10250 cycles. All the $\mu$ XCT scans were performed with the sample under maximum load. The effective voxel size of the reconstructed tomographs was 0.7 $\mu \mathrm{m}$. The resolution of the reconstructed DCT grain map was $1.75 \mu \mathrm{m}$.

\subsection{Digital Volume Correlation (DVC) analysis of 3D displacements}

The $\mu \mathrm{XCT}$ datasets were analysed with respect to a reference dataset (500 cycles; first dataset recorded) using digital volume correlation software (LaVision StrainMaster 8.1.6). This paper presents data for 1000, 3500 and 
This is the author's copy of a paper accepted for publication in the International Journal of Fatigue (http://dx.doi.org/10.1016/j.ijfatigue.2014.04.003)

10250 cycles, referred to as early, intermediate and final data. Cropped regions of the datasets at one notch were examined; each was $320 \times 260 \times 180$ voxels in size. DVC analysis provides a 3D displacement vector field on a discrete grid; the DVC analysis was performed on successively refined grids using with step-wise reducing size interrogation subsets; these were initially $128 \times 128 \times 128$ voxels (with $50 \%$ overlap with neighbouring interrogation subsets), then $64 \times 64 \times 64$ voxels ( $50 \%$ overlap) and finally $32 \times 32 \times 32$ voxels $(75 \%$ overlap). Three passes were performed at each step with each pass informing the interrogation subsets in the subsequent pass. The final displacement field was thus calculated with a grid separation distance of 24 voxels $(\sim 17 \mu \mathrm{m})$. A vigorous censorship criteria, requiring a correlation coefficient larger than 0.9 , was applied to eliminate displacement vectors with low accuracy.

\subsection{Post-Test Serial Block Face Scanning Electron Microscopy (SBFSEM)}

In order to obtain 3D images of the fatigue-tested specimens, sequential sectioning by ultramicrotomy within a scanning electron microscope chamber was performed; this technique is referred to as Serial Block Face Scanning Electron Microscopy (SBFSEM). The specimen was first trimmed with a conventional ultramicrotome (Leica EM UC6) in order to generate the appropriate region for imaging, then serial sections were generated with a diamond knife in a Quanta (FEI) 250 FEG-ESEM using an in situ ultramicrotome (Gatan, 3View). A total of 1000 individual images was acquired at a electron beam energy of $3 \mathrm{keV}$ using a backscattered electron detector. The resulting 3D SBFSEM dataset $(137.8 \times 137.8 \times 67 \mu \mathrm{m})$ had a voxel size of $\sim 70 \mathrm{~nm}$.

\section{Results}

\subsection{Comparison: SBFSEM and $\mu \mathrm{XCT}$}

It was not possible, due to experimental factors, for the SBFSEM sectioning to be done on planes that were parallel to slices in the $\mu \mathrm{XCT}$ dataset. The SBFSEM and $\mu \mathrm{XCT}$ datasets were therefore registered manually against each other by matching of significant precipitates, which appear bright in both imaging modes due to their high atomic number (the datasets were too complex to employ the automated registration algorithms in the software). The visualization and data manipulation (translation and rotation) were all done using commercial software (Avizo 8.0), employing clipping planes and transparency to explore the relationships between the datasets. The visualised planar sections were extracted from the image stack by interpolation, using the standard algorithms in the Avizo software.

An example of a raw scanning electron microscopy image of a single slice or stack in the SBFSEM data is shown in Figure 1a. This slice passes through the FIB-notch; it is not quite parallel to the notch plane; hence, the notch appears distorted to a rhomboid. The block face has very high quality, enabling highresolution imaging of the precipitates in the microstructure. The backscatter detector provides a degree of grain orientation contrast; intragranular bands of slightly different brightness (Figure 1b) are observed that deviate the crack path 
This is the author's copy of a paper accepted for publication in the International Journal of Fatigue (http://dx.doi.org/10.1016/j.ijfatigue.2014.04.003)

at their interfaces, and these are judged to be twins. The convoluted path of the crack, particularly close to the FIB notch causes some fragility and this has allowed some material to detach with fragments being visible within the notch, but otherwise the edge-retention of the crack is excellent. This is illustrated in the three-dimensional visualisation of the crack (Figure 1c), produced by greylevel (i.e. image intensity) segmentation to obtain an iso-surface. A highresolution description of the crack shape is obtained, except close to the notch in the damaged region. A slice through the SBFSEM data is compared with a slice of the $\mu \mathrm{XCT}$ data at the same position in Figure 1( $\mathrm{d}$ and e); the SBFSEM volume was smaller than the cropped $\mu \mathrm{XCT}$ volume. In addition to demonstrating the continuity of the crack surface (the lower-resolution $\mu \mathrm{XCT}$ cannot resolve the crack in some regions, particularly close to the highly attenuating Yt and Nd-rich precipitate as the small crack opening reduces the contrast) these show that fine rare earth precipitates are resolved by SBFSEM that are not observed by $\mu$ XCT, and also indicate changes in the fracture surface morphology in different grains. For instance, the crack shows a greater tendency for fine bifurcations before crossing a grain boundary, identified from its decoration by fine precipitates.

The high resolution of the SBFSEM data enables three-dimensional fractographic analysis; examples are shown in Figure 2 for locations (i) and (ii), which are indicated in Figure 1c. In each case, a pair of orthogonal vertical slices of the microstructure is shown, with a segment of the crack that is also presented as a zoomed image; no binning or smoothing has been applied to crack iso-surface. Location (i) (shown in Figure 2a-c) is a region where the crack is almost planar and inclined steeply to the tensile axis. The fine striated features, such as marked by arrow (1) in Figure 2c, are an artefact of the $70 \mathrm{~nm}$ image stack width of the dataset. Nonetheless, features that are characteristic of crystallographic cracking are observed, including, for example, river lines that are approximately parallel to the crack propagation direction marked by arrow (2) in Figure 2c, deflection of the crack plane at grain boundaries marked by arrow (3) in Figure $2 \mathrm{c}$ and deviations in the crack path at intersections with significant precipitates marked by arrow (4) in Figure 2c. Location (ii) (shown in Figure 2d-f) is a region where the crack path is approximately perpendicular to the tensile axis, but its surface is non-planar; a step-like structure is apparent, with separated regions of low roughness. The zoomed image (Figure 2f) reveals a three-dimensional structure of planar or slab-like features, indicated by arrows, which are bounded by cracks; these could not have been identified by conventional scanning electron microscopy of the fracture surface. Their shape is consistent with twins such as those observed in Figure 1b.

\subsection{DVC Measurement of Crack Opening Displacements}

The precision of the displacements measured by DVC was estimated using correlation between the reference ( 500 cycles) and early ( 1000 cycles) datasets; only rigid body movements should exist in this case, as there was negligible crack growth over this period [14]. The variances of the displacements within the region of the sample that excluded the notch (i.e. $\sim 200 \times 200 \times 200$ voxels) were $0.05,0.05$ and $0.07 \mu \mathrm{m}$ in the $x, y$ and $z$ directions respectively; the precision of the displacement measurement is thus judged to be $0.07 \mu \mathrm{m}$ or 0.1 
This is the author's copy of a paper accepted for publication in the International Journal of Fatigue (http://dx.doi.org/10.1016/j.ijfatigue.2014.04.003)

voxels. This is consistent with other reports of DVC precision [30], and it is judged to be an overestimate since the measured displacements across the volume are influenced by a small rigid body rotation. Rigid body rotations between the tomographs were measured using an in-house code (for details see [29]). No correction for rigid body rotation was necessary since the measured rotation angles were very small: i.e. $0.055^{\circ},-0.018^{\circ}$ and $0.015^{\circ}$ respectively about the $x, y$ and $z$ axes for the intermediate dataset (3500 cycles); and $0.042^{\circ}$, $0.014^{\circ}$ and $0.066^{\circ}$ for the final dataset (10250 cycles). Similarly, the maximum principal strain in this region, in which zero strain is expected, was found to be 0.004; this is judged to be an estimate of the precision of strain measurement.

To illustrate how three-dimensional data can be extracted, two orthogonal vertical sections through the 3D crack are examined. For each, the crack plane normal is close to the vertical section plane, such that the trace of the crack in the section represents closely the orientation of the crack plane relative to the tensile stress axis. The sections are shown in Figure 3 in relation to the DCT grain map and a three-dimensional visualisation of the crack observed in SBFSEM reconstruction. Section A is approximately parallel to the sample outer surface and section B is perpendicular; locations (i) and (ii) (from Figure 1c) are close to these sections. The traces of these sections with respect to the previously published data are shown in Figure 4, using adapted images from reference [14]. Data for the crack front development and the basal plane orientation in the grains encountered (Figure 4a), the crack plane orientation relative to the tensile axis and the crystal basal plane (Figure $4 \mathrm{~b}$ and $\mathrm{c}$ ), and the local crack growth rate (Figure $4 \mathrm{~d}$ ) are presented. In these Figures, the crack is visualised by its projected area, viewed along the tensile axis; the DCT-derived grain boundaries are shown where they intersect the crack, and so they do not necessarily correspond with the grains that are visualised in the planar sections. The correspondence between the mappings of the grain boundaries by DCT with the positions of the grain boundaries that are decorated by precipitates is fair (Figure 3a). This is expected, since the grain boundaries are not well defined from the edges of the diffraction spots that are used in DCT grain mapping; expansion of the mapped grains is applied to fill space during the microstructure reconstruction and the positions of grain boundaries can thus be in error [10].

The DVC-measured displacement fields at the intermediate (3500 cycles) and final $(10250$ cycles $)$ stages, with respect to the xyz coordinates of the $\mu$ XCT dataset, are shown in Figure 5 and Figure 6 for the A and B orthogonal sections. The largest displacements are in the vertical $z$-direction, parallel to the applied load, and visualisations of the displacements and the maximum principal strain field in the two orthogonal sections are shown in Figure 7; the strain is obtained by the finite difference method from the displacement field. These images, which are composites of different data types, are not fully quantitative; hot colours indicate larger displacements and cold colours smaller displacements with the same range for each figure. In order to present quantitative data on the crack openings, several line profiles (1 to 5) across the crack are identified along which the three-dimensional displacements have been measured. The positions and orientations of these profiles are marked in Figure 3, and the measured displacements in local coordinates $\eta, \phi, \xi$ (see Figure 3a) in the intermediate 
This is the author's copy of a paper accepted for publication in the International Journal of Fatigue (http://dx.doi.org/10.1016/j.ijfatigue.2014.04.003)

and final datasets are presented in Figure 8. The profiles are approximately perpendicular to the crack traces; hence, three components of crack opening displacement are obtained, namely the mode I opening displacement perpendicular to the crack plane ( $\psi$ ), the mode II shear displacement parallel to the crack trace in the plane of the section $(\eta)$ and the orthogonal mode III shear displacement that is out of the section plane $(\xi)$. The displacements presented in the sections and the line profiles are obtained using bilinear interpolations between neighbouring sets of four data points from the DVC dataset, which have a grid spacing of 8 voxels or $\sim 6 \mu \mathrm{m}$. The observed profiles show an increased gradient across the crack, identified by the peak in maximum principal strain, whereas the true displacement profile across a crack is a step-function. Digital volume correlation measurements close to features such as cracks may be in error due to overlap of interrogation subsets with the discontinuity [34], so the obtained values along the line profiles should be regarded as approximate.

In section $A$, to the left of the notch, the crack plane is inclined to the vertical applied stress by approximately $45^{\circ}$ (Figure $4 \mathrm{c}$ ) and the crack plane is within $30^{\circ}$ of the basal plane (Figure 4b). Profile 1 is located in a grain with Schmid factor close to 0.3 [14]. The displacements along profile 1 , which is crossed by the crack in the intermediate dataset at 3500 cycles, initially show a small mode I opening $(<0.1 \mu \mathrm{m})$. As the crack propagates further by the final dataset at 10250 cycles, the crack opening at profile 1 increases to the order of $0.6 \mu \mathrm{m}$, remaining predominantly mode I, with in-plane and out-of plane shear displacements (modes II and III) of around $0.2 \mu \mathrm{m}$.

Immediately to the right of the notch in section $\mathrm{A}$, the normal of crack plane is close to the applied stress (Figure 4c); after crossing the grain boundary between profiles 2 and 3 , the crack propagates at an angle of approximately $60^{\circ}$ to the tensile axis. The Schmid factor in both grains is close to 0.3 , being slightly lower in the second than the first [14]. At the position of profile 2, there is a large angle $\left(>75^{\circ}\right)$ between the crack and the basal plane, whilst at profile 3 they are close to parallel (Figure $4 \mathrm{~b}$ ). In profile 2 , mixed modes of crack opening are observed; a mode II in-plane shear displacement of $\sim 0.5 \mu \mathrm{m}$ is dominant in the intermediate dataset at 3500 cycles, increasing to $1.5 \mu \mathrm{m}$ by the final stage of 10250 cycles; there are increases in modes I and III to approximately $0.25 \mu \mathrm{m}$. At profile 3 , which is not reached by the crack at 3500 cycles, the opening at 10250 cycles of over $0.6 \mu \mathrm{m}$ is predominantly mode I, with a small component $(\sim 0.25 \mu \mathrm{m})$ of mode III. The highest crack growth rate was measured as the crack crosses profile 3 (Figure $4 \mathrm{~d}$ ).

In the orthogonal section B, the crack plane is approximately perpendicular to the applied stress. There is a substantial increase in the Schmid factor between the grains at profiles 4 and 5 from approximately 0.3 to close to 0.5 [14]. At profile 4 , the predominant mode I opening of approximately $0.5 \mu \mathrm{m}$ at 3500 cycles increases significantly to around $1.5 \mu \mathrm{m}$ by 10250 cycles, with no significant mode II and mode III components of opening displacement. At profile 5 , which is not reached by the crack at 3500 cycles, the mode I opening displacement is approximately $0.75 \mu \mathrm{m}$ at 10500 cycles with some mode III 
This is the author's copy of a paper accepted for publication in the International Journal of Fatigue (http://dx.doi.org/10.1016/j.ijfatigue.2014.04.003)

shear. This opening displacement is smaller than measured at profile 4 , which is closer to the notch.

\section{Discussion}

This study has shown that SBFSEM can provide high-resolution, threedimensional destructive characterisation of a volume that is sufficiently large to investigate the interaction between a short fatigue crack and the microstructure of an engineering alloy. The agreement between the microstructure and crack data, when observed by both SBFSEM and X-ray computed micro-tomography $(\mu \mathrm{XCT})$, shows that the non-destructive technique of $\mu \mathrm{XCT}$ provides a good description of the crack shape and the more significant microstructural features such as coarse precipitates of high atomic number, although the finer precipitates are not well resolved. The comparison of the high-resolution SBFSEM observations of precipitate distributions, which tend to decorate grain boundaries, with grain mapping by Diffraction Contrast Tomography (DCT) confirms that DCT characterisation of grain shapes is approximate, due to the need to expand the incompletely observed grain shapes to fill space.

The high resolution of SBFSEM is sufficient for fractographic analysis of the mode of crack propagation; flat cleavage-like fracture is observed when the crack plane is close to the basal plane orientation, which is identified using the DCT data on grain orientations. The previous study [14] found the crack growth rate was fastest when the crack plane was close to the basal plane (e.g. at the locations of profiles 1 and 5). More complex fractography and slower crack growth is observed when the crack path is not close to the basal plane; the stepwise propagation might be inferred from the $\mu \mathrm{XCT}$ observations to be along alternate crystal planes. However, secondary cracking is also seen, which would not be readily observed by conventional fractography in a scanning electron microscope; its morphology shows that cracking has occurred along sets of nearparallel interfaces, which are a characteristic of twins. Deformation twinning occurs readily in magnesium under static and cyclic loading [35] [36] and the band-like features observed in the SBFSEM image slices are deduced to be twins that are visible due to orientation contrast in the backscatter image. Twinning in magnesium has been observed to strongly influences the fracture path [37]. The observed deviations in the crack path in this work shows that twin formation is a mechanism that may influence crack propagation in suitable oriented grains. A detailed interpretation of the relationship between twinning, grain orientation and crack development in this sample has not been attempted, due to their low visibility. Recently, SBFSEM surfaces have been shown to be suitable for electron backscatter diffraction (EBSD) analysis of grain orientations ${ }^{1}$, and a future investigation could provide a high-resolution three-dimensional grain map in

${ }^{1}$ Unpublished data: T. Hashimoto and G.E. Thompson. 
This is the author's copy of a paper accepted for publication in the International Journal of Fatigue (http://dx.doi.org/10.1016/j.ijfatigue.2014.04.003)

which the twin variants may be identified. This would provide data for a quantitative study of the influence of twinning on crack propagation.

The digital volume correlation analysis of the $\mu \mathrm{XCT}$ datasets has measured the displacements between the original undamaged material and the opening of the crack under load. Consequently the local modes of crack opening have been determined for the first time in a short fatigue crack in 3D. The modes of crack opening vary with the crack orientation and location due to the influence of the crack shape. For most of the cases examined, the dominant component of crack opening is mode I; the case with a dominant shear opening (10250 cycles, Profile 2, Figure 3) (Figure 8b) is due to the geometric effect of the opening of the inclined crack beyond (Profile 3, Figure 3), which is propagating close to the crystallographic basal plane. The crack opening for that inclined crack shows mixed-mode loading, with a dominant mode I component (Figure 8c). In metals, crystallographically oriented fatigue cracks are commonly considered to demonstrate shear-controlled stage I crack propagation, and so develop along slip planes [16] [17]. The basal plane in magnesium is the plane of easiest slip and it is not observed to be a cleavage plane [37], although slip-induced cleavage has been postulated in tension-compression fatigue [38]. It is also the plane observed to experience more rapid fatigue crack propagation in a single crystal study [39]. Consequently, in the previous study of this sample [14], it was deduced that the observed crystallographic cracking was stage I fatigue, operating by basal plane slip in grains of suitably high Schmid factor. However, although the crack openings measured for this basal plane crack have a component of the expected shear displacements, there is a more significant mode I opening. The displacements measured here are dominated by the elastic deformation of the crack, since the plastic strains at the crack tip will be small and localised. Nonetheless, the elastic displacements describe the loading on the crack tip that drives crack propagation. Basal plane short fatigue crack propagation therefore occurs readily with a significant component of mode I crack opening. At the present time, it cannot be concluded if the mode I component is redundant, or whether it affects the crack propagation rate. We suggest that future experiments using the methods demonstrated here, particularly following the crack openings during fatigue cycles, might investigate the local relationships between the magnitudes of mixed-mode loading, the crack growth rate and the grain orientation. The data could improve the fidelity and validity of crystal-plasticity based short fatigue crack models.

\section{Conclusion}

Serial Block Face Scanning Electron Microscopy (SBFSEM) has been applied to a sample from a previous four-dimensional in situ study of a short crack in a magnesium alloy. This enabled very high-resolution post-test examination of a sufficient volume that was sufficient to provide three-dimensional characterisation of the crack shape and topography (i.e. fractography). This has been used to investigate the influence of microstructural features on the crack propagation rates, which had been previously measured from synchrotron X-ray computed microtomographs, following the crack's three-dimensional 
This is the author's copy of a paper accepted for publication in the International Journal of Fatigue (http://dx.doi.org/10.1016/j.ijfatigue.2014.04.003)

development with progressive fatigue cycling. The microstructure had been mapped by diffraction contrast tomography to measure grain shapes and crystal orientations in three-dimensions.

Digital volume correlation, applied to the X-ray computed tomography datasets, measured the three-dimensional crack opening displacements and, hence, the crack opening modes. Crystallographic cracks in magnesium propagate with mixed mode opening. Basal plane fracture is a dominant fatigue mechanism, hence the tilt/twist of the basal plane at grain boundaries and crack deflection at twin interfaces are important factors that will affect short fatigue crack propagation rates in magnesium.

\section{Acknowledgements}

The X-ray tomography data were obtained in Experiment MA423 at the European Synchrotron Radiation Facility (ESRF) as part of the UK Engineering and Physical Sciences Research Council (EPSRC) supported project "Crack Nucleation and Short Crack Behaviour by Non-destructive In-situ Observation" (EP/C002946/1). The magnesium alloy was kindly supplied by Magnesium Elektron Ltd. The support of the UK Engineering and Physical Sciences Research Council (EPSRC) via the LATEST2 (Light Alloys Towards Environmentally Sustainable Transport: 2nd Generation) Programme Grant (EP/H020047/1) is acknowledged. TJM and MM acknowledge the support of the Oxford Martin School.

\section{Figures}

Figure 1: Comparison of SBFSEM and $\mu$ XCT datasets: a) original image slice of SBFSEM dataset; b) enhanced image showing intragranular bands of differential back-scatter contrast, c) 3-dimensional visualisation of the crack, segmented from the SBFSEM dataset; d) SBFSEM data overlaid on $\mu$ XCT data after registering in 3D; d) enlarged images from e) to show more clearly the comparison of SBFSEM with $\mu$ XCT.

Figure 2: Visualisation of the crack using the SBFSEM dataset at two locations, which are identified in Figure 1. At location (i) a planar crack inclined to the tensile axis is observed: a) vertical slices; b) iso-surface of the crack; and c) zoomed image to show resolution and certain features: (1) artefacts due to the image stack; (2) river line; (3) deflection at a grain boundary and (4) deflection at a precipitate . At location (ii), a non-planar crack approximately orthogonal to the tensile axis is observed; d) vertical slices; e) iso-surface of the crack ; and f) zoomed image to show resolution and planar features that are indicated by arrows..

Figure 3: Identification of orthogonal sections and their reference points in the 3D datasets: a) vertical sections A and B through the $\mu$ XCT and DCT datasets (the $\mu$ XCT data at the final stage are overlaid on the grain map obtained by DCT in which grains are assigned different colours); b) the traces of sections A and B are shown on a horizontal plane through the $\mu$ XCT and DCT datasets with references points 1 to 5 marked; c) the traces of sections $A$ and $B$ and the reference points are shown on a 3D visualisation of the crack, obtained from the SBFSEM data.

Figure 4: Data on the fatigue crack propagation and orientation from [14] annotated with the positions of sections $A$ and $B$ and the profiles 1 to 5 (the positions of these are marked and labelled in Figure 3b): a) data for the crack front development with progressive observations and the basal plane orientation in the grains encountered (the inset figure shows how the angular rotation of the basal plane normal about the z-axis determines the colour; the saturation of the colour, from white to near-black, depends on the angle between the basal plane normal and the z-axis. Grains in which 
This is the author's copy of a paper accepted for publication in the International Journal of Fatigue (http://dx.doi.org/10.1016/j.ijfatigue.2014.04.003)

the basal plane is perpendicular to the tensile axis are lightest.); b) the local orientation of the crack plane, using the same colour map as in a); c) the deviation of the crack plane from the basal plane and d) the local crack growth rate. The colour map inset in a) shows the orientation of the basal plane, while that in c) shows the crack plane orientation (both stereographic projection).

Figure 5: DVC measurement of displacements in the $\mu$ XCT dataset in section A (see Figure 3) relative to the reference dataset at $\mathbf{5 0 0}$ cycles; left column at 3500 cycles (intermediate dataset), right column at 10250 cycles (final dataset). The DVC data are superposed on the slice through the $\mu$ XCT dataset, which is shown in a) for clarity; b) $x$-displacement; c) $y$-displacement; d) $z$-displacement The scale for the DVC data is qualitative (hot colours are higher values). Quantitative data are given in Figure 8.

Figure 6: DVC measurement of displacements in the $\mu$ XCT dataset in section B (see Figure 3), relative to the reference dataset at $\mathbf{5 0 0}$ cycles; left column at 3500 cycles (intermediate dataset), right column at 10250 cycles (final dataset). The DVC data are superposed on the slice through the $\mu$ XCT dataset, which is shown in a) for clarity; b) $x$-displacement; c) $y$-displacement; d) $z$-displacement. The scale for the DVC data is qualitative (hot colours are higher values). Quantitative data are given in Figure 8.

Figure 7: Visualisations of digital volume correlation measurement of crack opening behaviour on the orthogonal planes of sections A and B (see Figure 3): a) z-displacement; b) maximum principa strain. The scale is qualitative (hot colours are higher values). Quantitative data are given in Figure 8.

Figure 8: Deformation measured along line profiles in sections A and B (see Figure 3) at 3500 cycles (left, intermediate dataset) and 10250 cycles (right, final dataset): a) profile 1; b) profile 2; c) profile 3 ; d) profile 4; and e) profile 5 . The relative displacements provide the mode I opening, mode II inplane shear and mode III out-of-plane shear; the maximum principal strain is also shown.

\section{References}

[1] P. Neumann, Coarse slip model of fatigue, Acta Metallurgica 17 (1969) 1219-1225.

[2] J. C. Newman, The merging of fatigue and fracture mechanics concepts : a historical perspective, Aerospace Sciences, 34 (1998) 347-390.

[3] D. L. McDowell and F. P. E. Dunne, Microstructure-sensitive computational modelling of fatigue crack formation, International Journal of Fatigue 32 (2010) 1521-1542.

[4] S. R. Stock, X-ray microtomography of materials, International Materials Review 44 (1999) 141-164.

[5] E. Maire, J.-Y. Buffière, L. Salvo, J. J. Blandin, W. Ludwig, and J. M. Letang, On the application of X-ray microtomography in the field of materials science, Advanced Engineering Materials 3 (2001) 539-546.

[6] W. Ludwig, J-Y. Buffière, S. Savelli and, P. Cloetens, P. Study of the interaction of a short fatigue crack with grain boundaries in a cast $\mathrm{Al}$ alloy using X-ray microtomography. Acta Mater 51 (2003) 585-598.

[7] T. J. Marrow, J.-Y. Buffière, P. J. Withers, G. Johnson and D. Engelberg, X-ray tomography of short fatigue crack nucleation in austempered ductile cast iron, International Journal of Fatigue 26 (2004) 717-725.

[8] J.-Y. Buffière, E. Ferrie, H. Proudhon and W. Ludwig, Three-dimensional visualisation of fatigue cracks in metals using high resolution synchrotron X-ray microtomography, Materials Science and Technology 22 (2006) 1019-1024. 
This is the author's copy of a paper accepted for publication in the International Journal of Fatigue (http://dx.doi.org/10.1016/j.ijfatigue.2014.04.003)

[9] M. Herbig, A. King, P. Reischig, H. Proudhon, E. M. Lauridsen, J. Marrow, J.-Y. Buffière and W. Ludwig, 3-D growth of a short fatigue crack within a polycrystalline microstructure studied using combined diffraction and phase-contrast X-ray tomography, Acta Materialia 59 (2011) 590-601.

[10] G. Johnson, A. King, Honnicke, J. Marrow and W. Ludwig, X-ray diffraction contrast tomography: a novel technique for three-dimensional grain mapping of polycrystals. II. The combined case, Journal of Applied Crystallography 41 (2008) 310-318.

[11] M. Herbig, A. King, P. Reischig, H. Proudhon, E. M. Lauridsen, J. Marrow, J.-Y. Buffière and W. Ludwig, 3-D growth of a short fatigue crack within a polycrystalline microstructure studied using combined diffraction and phase-contrast X-ray tomography, Acta Materialia 59 (2011) 590-601.

[12] A. King, G. Johnson, D. Engelberg, W. Ludwig and J. Marrow, Observations of intergranular stress corrosion cracking in a grain-mapped polycrystal, Science 321 (2008) 382-385.

[13] D. Gonzalez, A. King, M. Mostafavi, P. Reischig, S. R. du Roscoat, , W. Ludwig, J. Quinta da Fonseca, P.J. Withers and T. J. Marrow, Three-dimensional observation and image-based modelling of thermal strains in polycrystalline alumina. Acta Materialia, 61 (2013) 7521-7533.

[14] A. King, W. Ludwig, M. Herbig, J.-Y. Buffière, A. A. Khan, N. Stevens and T. J. Marrow. Three-dimensional in situ observations of short fatigue crack growth in magnesium. Acta Materialia, 59 (2011) 6761-6771

[15] D. L. Davidson and J. Lankford. Fatigue crack growth in metals and alloys: mechanisms and micromechanics. International Materials Reviews, 37 (1992) 45-76.

[16] P. A. S. Reed, X. D. Wu and I. Sinclair, Fatigue crack path prediction in UDIMET 720 nickel-based alloy single crystals. Metallurgical and Materials Transactions A: Physical Metallurgy and Materials Science, 31 (2000) 109123.

[17] A. J. Wilkinson, S. G. Roberts and P. B. Hirsch, Modelling the threshold conditions for propagation of stage I fatigue cracks. Acta Materialia, 46 (1998) 379-390.

[18] B. Künkler, O. Düber, P. Köster, U. Krupp, C.-P. Fritzen and H.-J. Christ, Modelling of short crack propagation - Transition from stage I to stage II, Engineering Fracture Mechanics, 75 (2008) 715-725.

[19] S. Al Shahrani and T. J. Marrow, Influence of Twins on Short Fatigue Cracks in Type 316L Stainless Steel. Key Engineering Materials, 465 (2011) 507510.

[20] C. J. Taylor, T. Zhai, A. J. Wilkinson and J. W. Martin, Influence of grain orientations on the initiation of fatigue damage in an Al-Li alloy Journal of Microscopy 195 (1999) 239-247.

[21] V. P. Bennett and D. L. McDowell, Polycrystal orientation distribution effects on microslip in high cycle fatigue. International Journal of Fatigue, 25 (2003) 27-39.

[22] E. Ferrié, J.-Y. Buffière, W. Ludwig and A. Gravouil, X-ray micro-tomography coupled to the extended finite element method to investigate microstructurally short fatigue cracks. Materials Science Forum, 567-568, (2008) 301-304. 
This is the author's copy of a paper accepted for publication in the International Journal of Fatigue (http://dx.doi.org/10.1016/j.ijfatigue.2014.04.003)

[23] W. Schaef, M. Marx, H. Vehoff, A. Heckl and P. Randelzhofer, A 3-D view on the mechanisms of short fatigue cracks interacting with grain boundaries Acta Materialia, 59 (2011) 1849-1861.

[24] T. Hashimoto, X. Zhou, C. Luo, K. Kawano, G. E. Thompson, A. E. Hughes, P. Skeldon, P. J. Withers, T. J. Marrow and A. H. Sherry, Nanotomography for understanding materials degradation. Scripta Materialia, 63 (2010). 835838.

[25] B. K. Bay, T. S. Smith, D. P. Fyhrie and M. Saad, Digital volume correlation: three-dimensional strain mapping using X-ray tomography. Exp Mech. 39 (1999) 217-226.

[26] N. Limodin, J. Réthoré, J.-Y. Buffière, F. Hild, S. Roux, W. Ludwig, J. Rannou and $\mathrm{A}$. Gravouil, Influence of closure on the 3D propagation of fatigue cracks in a nodular cast iron investigated by X-ray tomography and 3D volume correlation. Acta Materialia, 58 (2010) 2957-2967.

[27] F. Forsberg and C. R. Siviour, 3D deformation and strain analysis in compacted sugar using x-ray microtomography and digital volume correlation Measurement Science and Technology, 20 (2009) art. no. 095703.

[28] Y. Barranger, P. Doumalin, J.-C. Dupre, A. Germaneau, S. Hedan and V. Valle, Evaluation of three-dimensional and two-dimensional full displacement fields of a single edge notch fracture mechanics specimen, in light of experimental data using X-ray tomography. Engineering Fracture Mechanics, 76 (2009) 2371-2383.

[29] M. Mostafavi, Y. Vertyagina, C. Reinhard, R. Bradley, X. Jiang, M. Galano, J. Marrow, 3D Studies of Indentation by Combined X-Ray Tomography and Digital Volume Correlation, Key Engineering Materials, 592-593 (2013) 1421.

[30] F. Pierron, S.A. McDonald, D. Hollis, J. Fu, P. J. Withers and A. Alderson, A., Comparison of the mechanical behaviour of standard and auxetic foams by $\mathrm{X}$-ray computed tomography and digital volume correlation. Strain, 49 (2013) 1-16.

[31] M. Mostafavi, N. Baimpas, E. Tarleton, R. C. Atwood, S. A. McDonald, A. M. Korsunsky and T. J. Marrow, Three-dimensional crack observation, quantification and simulation in a quasi-brittle material. Acta Materialia, 61 (2013) 6276-6289.

[32] M. Mostafavi, S. A. McDonald, H. Çetinel, P. M. Mummery and T. J. Marrow, Flexural strength and defect behaviour of polygranular graphite under different states of stress. Carbon, 59 (2013) 325-336.

[33] P. Leplay, J. Réthoré, S. Meille, M.-C. Baietto, J. Adrien, J. Chevalier and E. Maire, Three-dimensional Analysis of an In Situ Double-torsion Test by Xray Computed Tomography and Digital Volume Correlation, Experimental Mechanics, 53 (2013) 1265-1275.

[34] J. Poissant, F. Barthelat, A novel "subset splitting" procedure for digital image correlation on discontinuous displacement fields Experimental Mechanics, 50 (2010) 353-364.

[35] M. R. Barnett, Twinning and the ductility of magnesium alloys: Part I: "Tension" twins, Materials Science and Engineering: A, 464, (2007) 1-7.

[36] L. Wu, A. Jain, D. W. Brown, G. M. Stoica, S. R. Agnew, B. Clausen, D.E. Fielden and P. K. Liaw, Twinning-detwinning behavior during the strain- 
This is the author's copy of a paper accepted for publication in the International Journal of Fatigue (http://dx.doi.org/10.1016/j.ijfatigue.2014.04.003)

controlled low-cycle fatigue testing of a wrought magnesium alloy, ZK60A, Acta Materialia, 56 (2008) 688-695.

[37] R. E. Reed-Hill, W. D. Robertson, The crystallographic characteristics of fracture in magnesium single crystals, Acta Metallurgica, 5 (1957) 728-737.

[38] Q. Yu, J. Zhang, Y. Jiang, Fatigue damage development in pure polycrystalline magnesium under cyclic tension-compression loading, Materials Science and Engineering A, 528 (2011) 7816-7826.

[39] S. Ando, K. Saruwatari, T. Hori, H. Tonda, Fatigue crack propagation behavior in magnesium single crystals, Nippon Kinzoku Gakkaishi/Journal of the Japan Institute of Metals, 67 (2003) 247-251 
a)

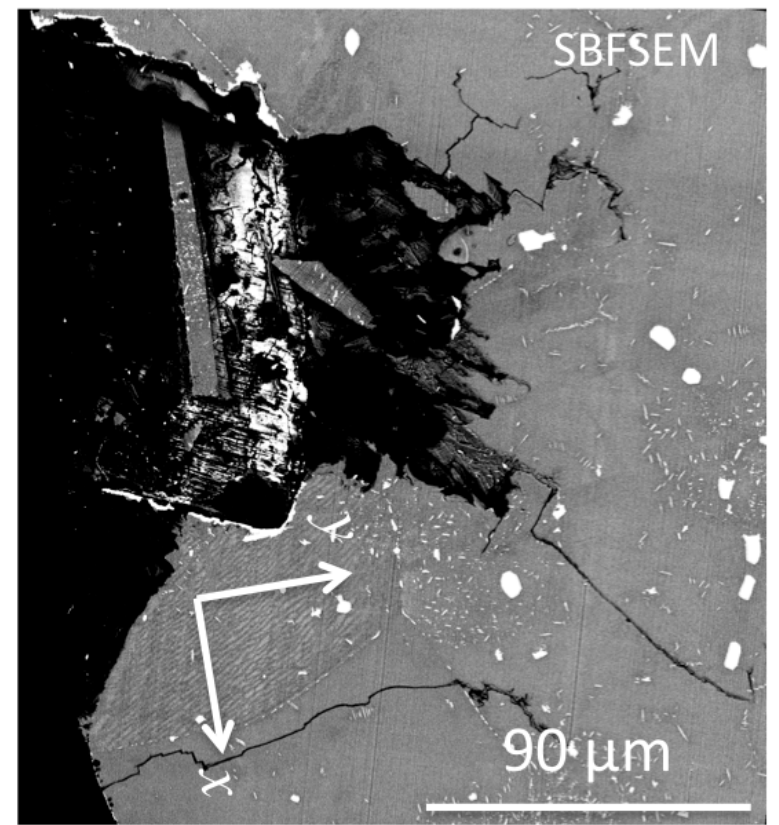

d)

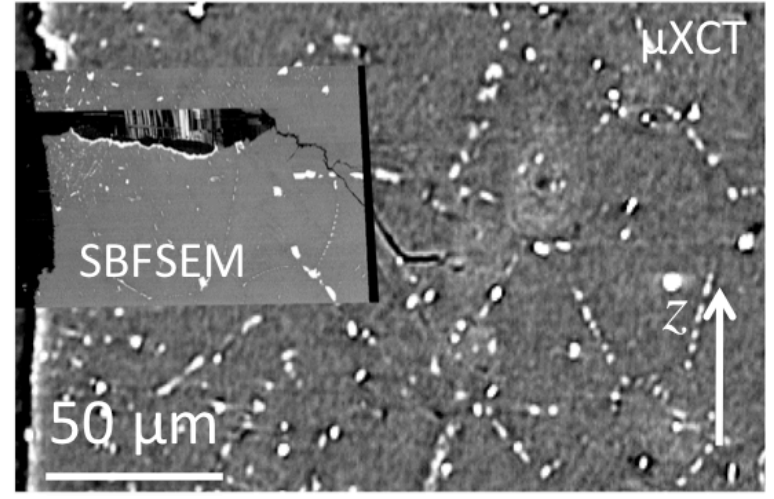

e)

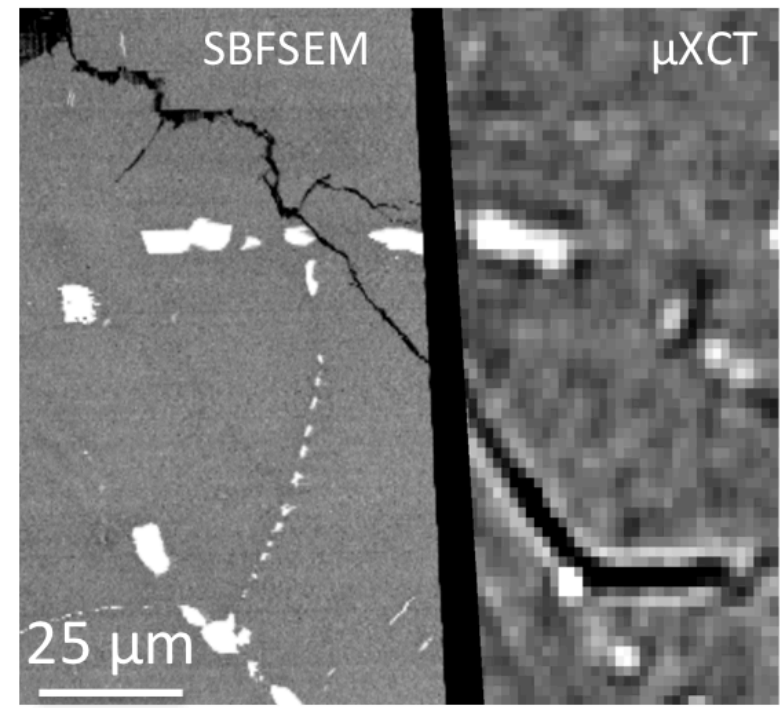

b)
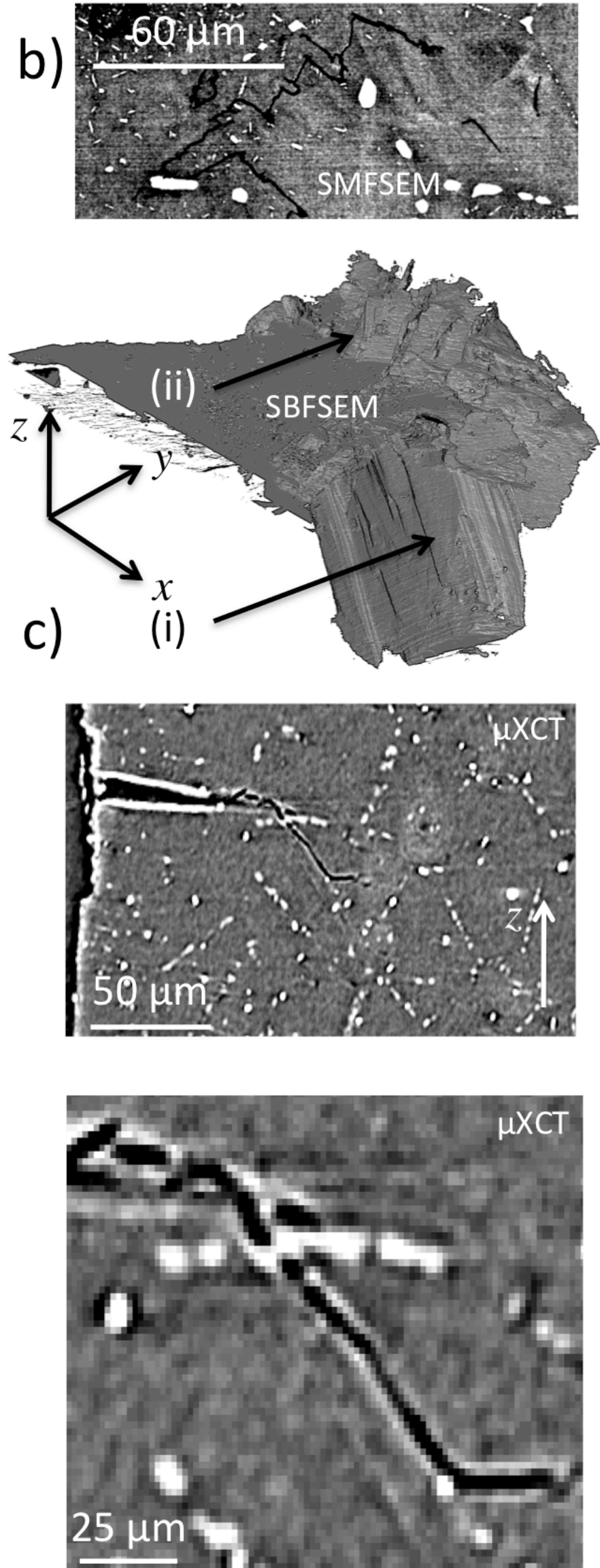

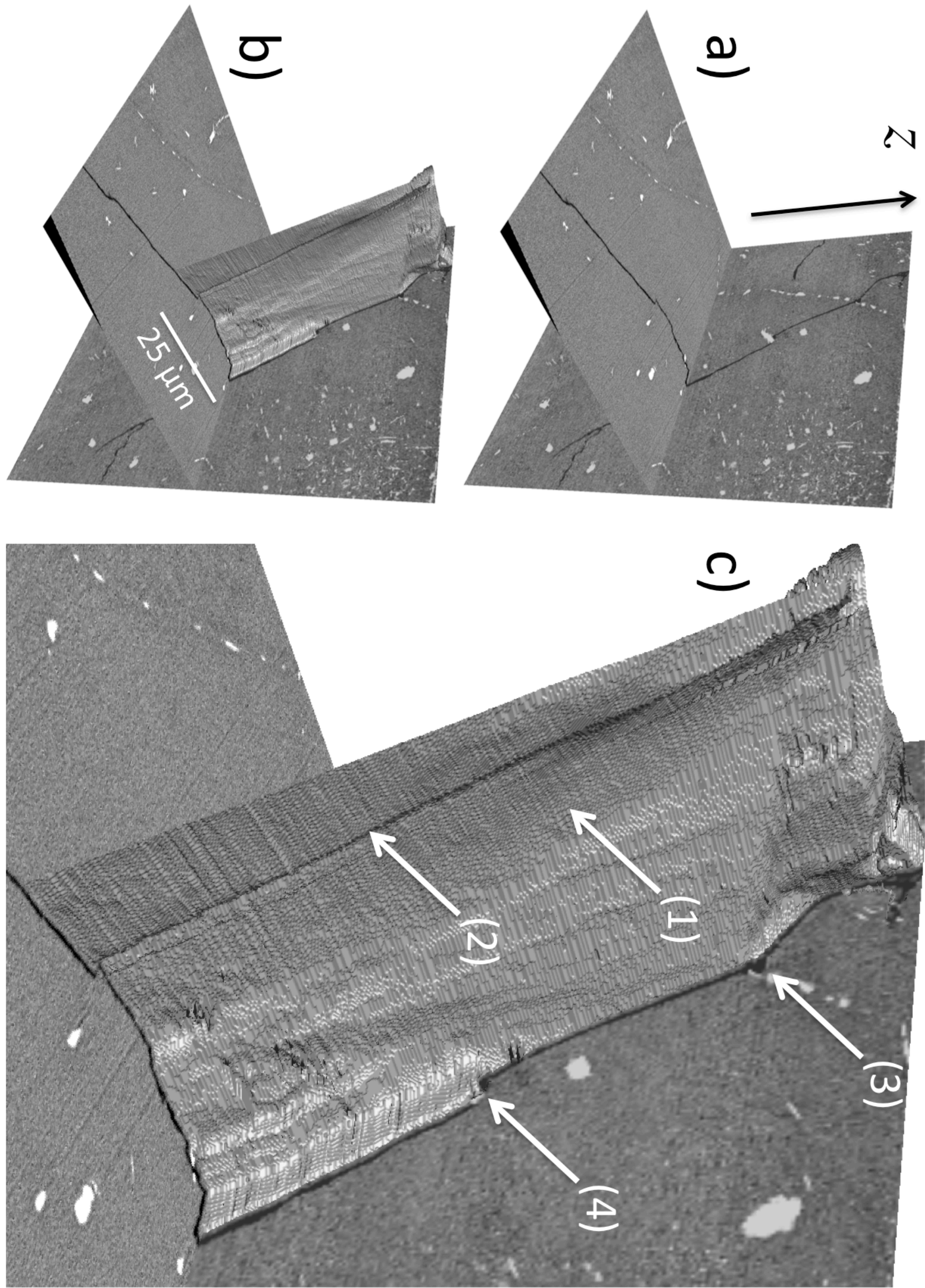

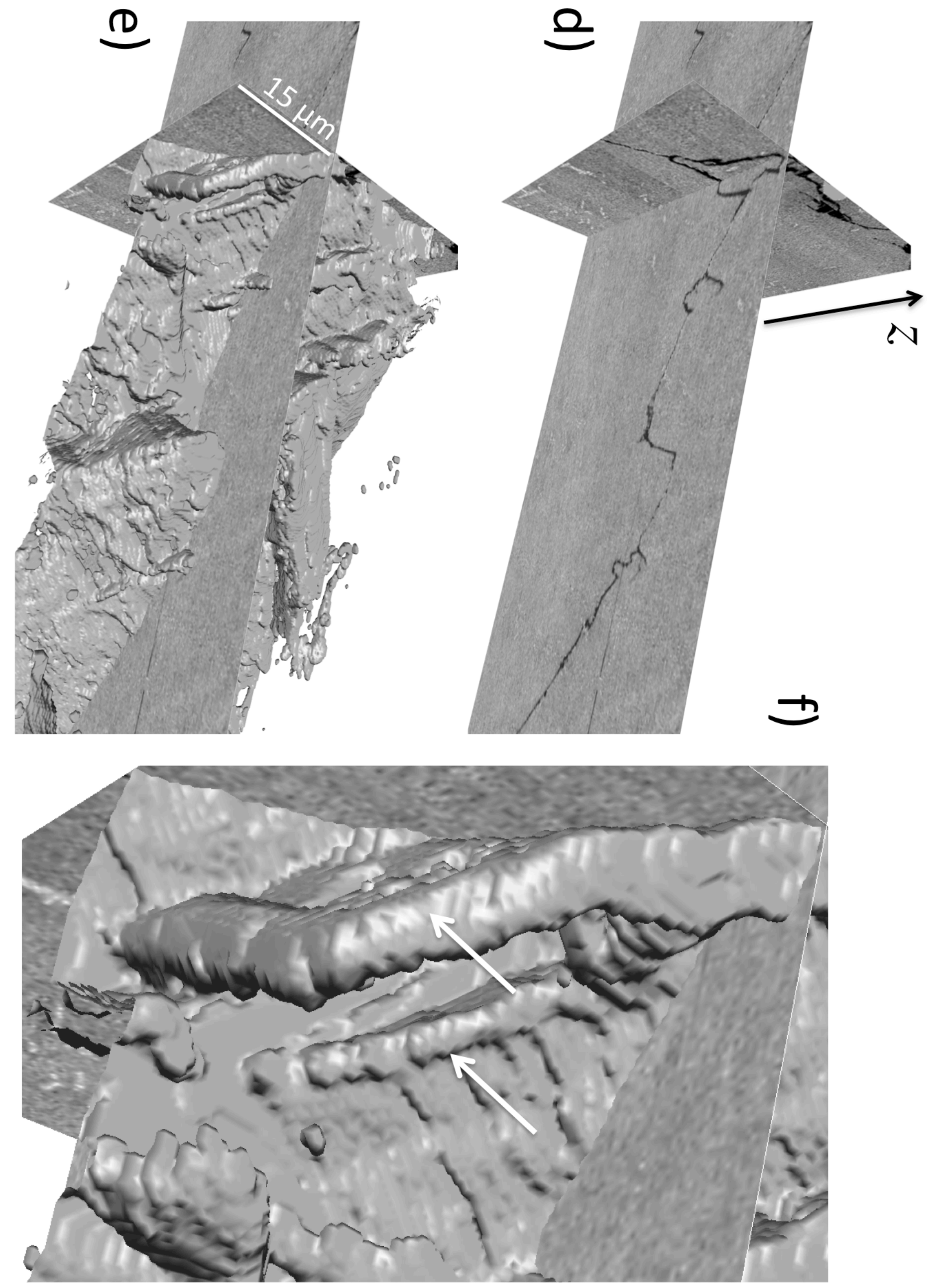

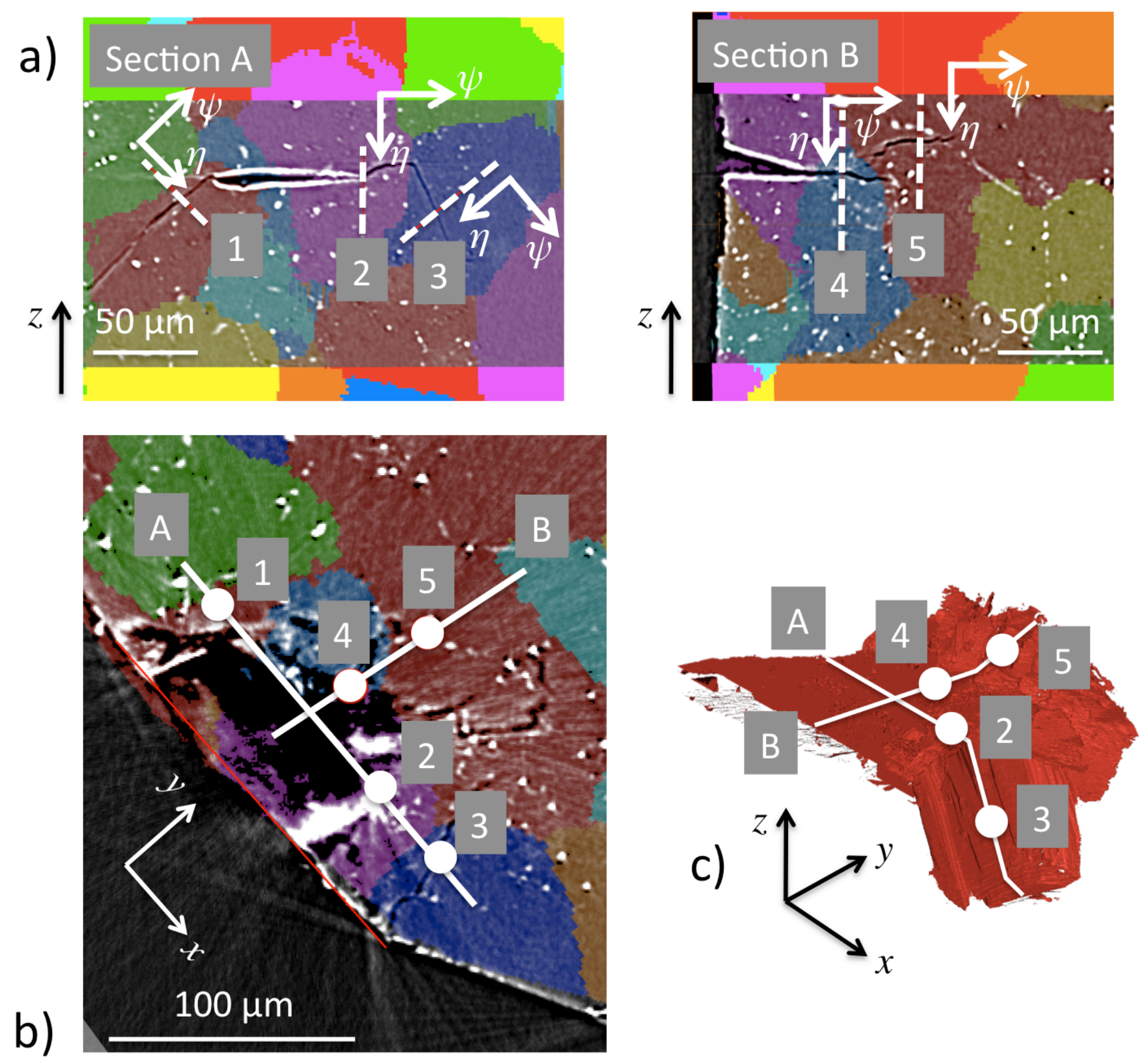


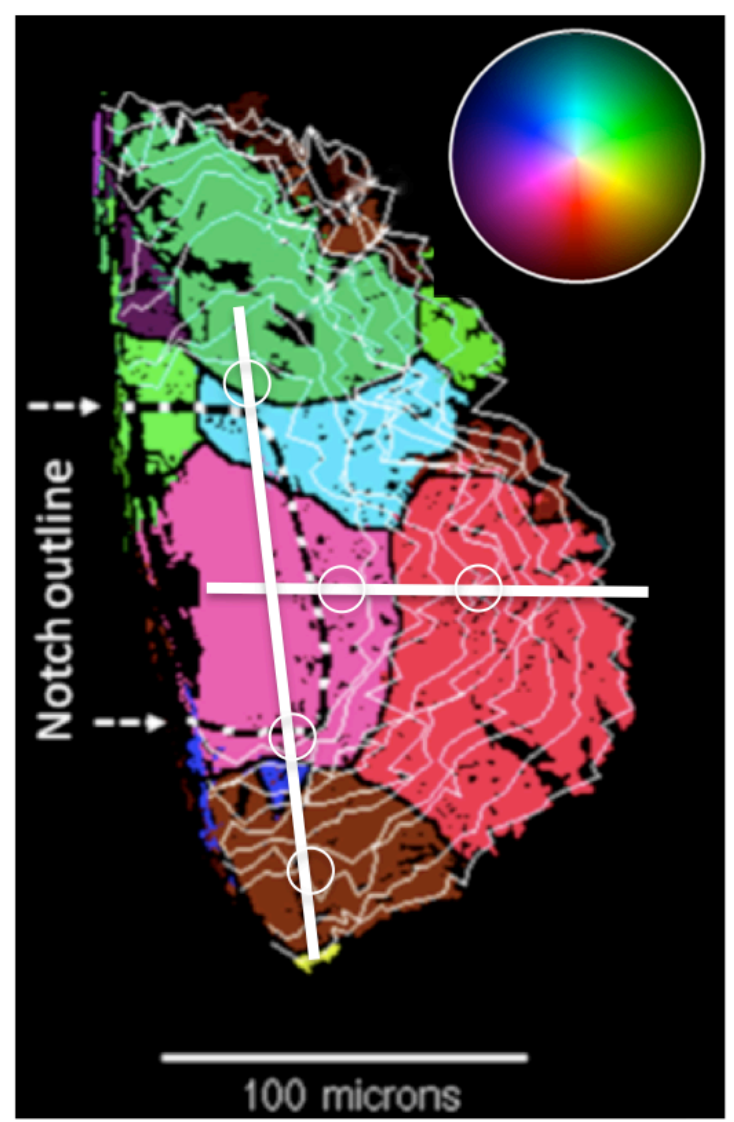

a)

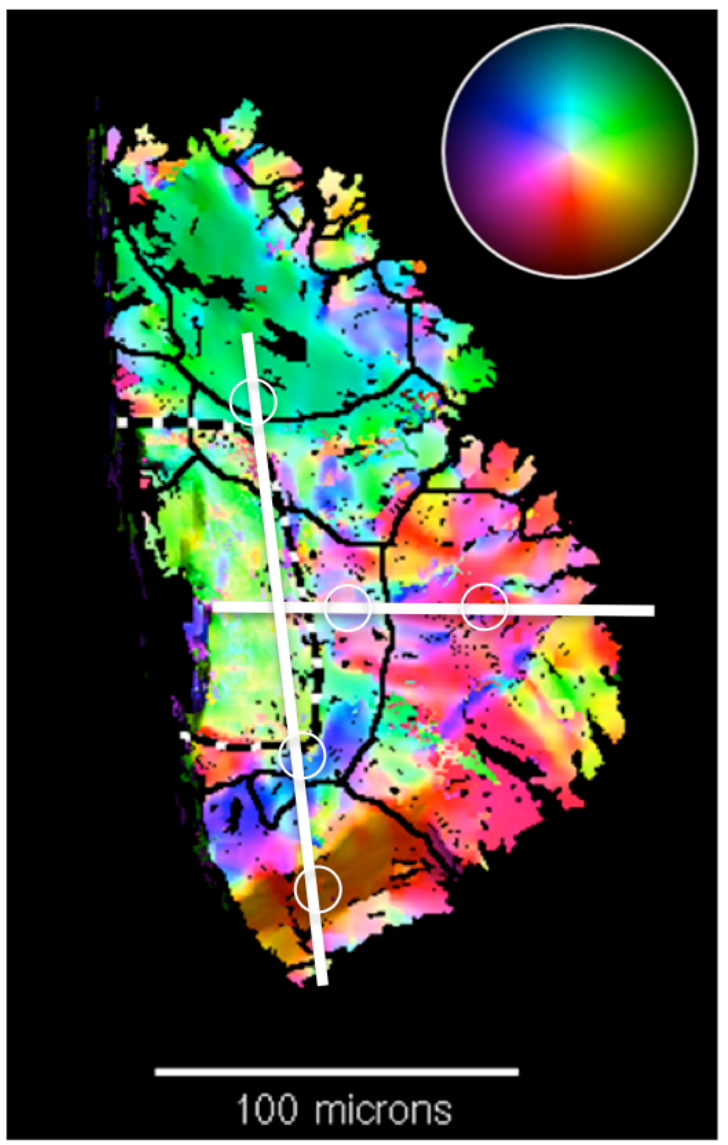

c)
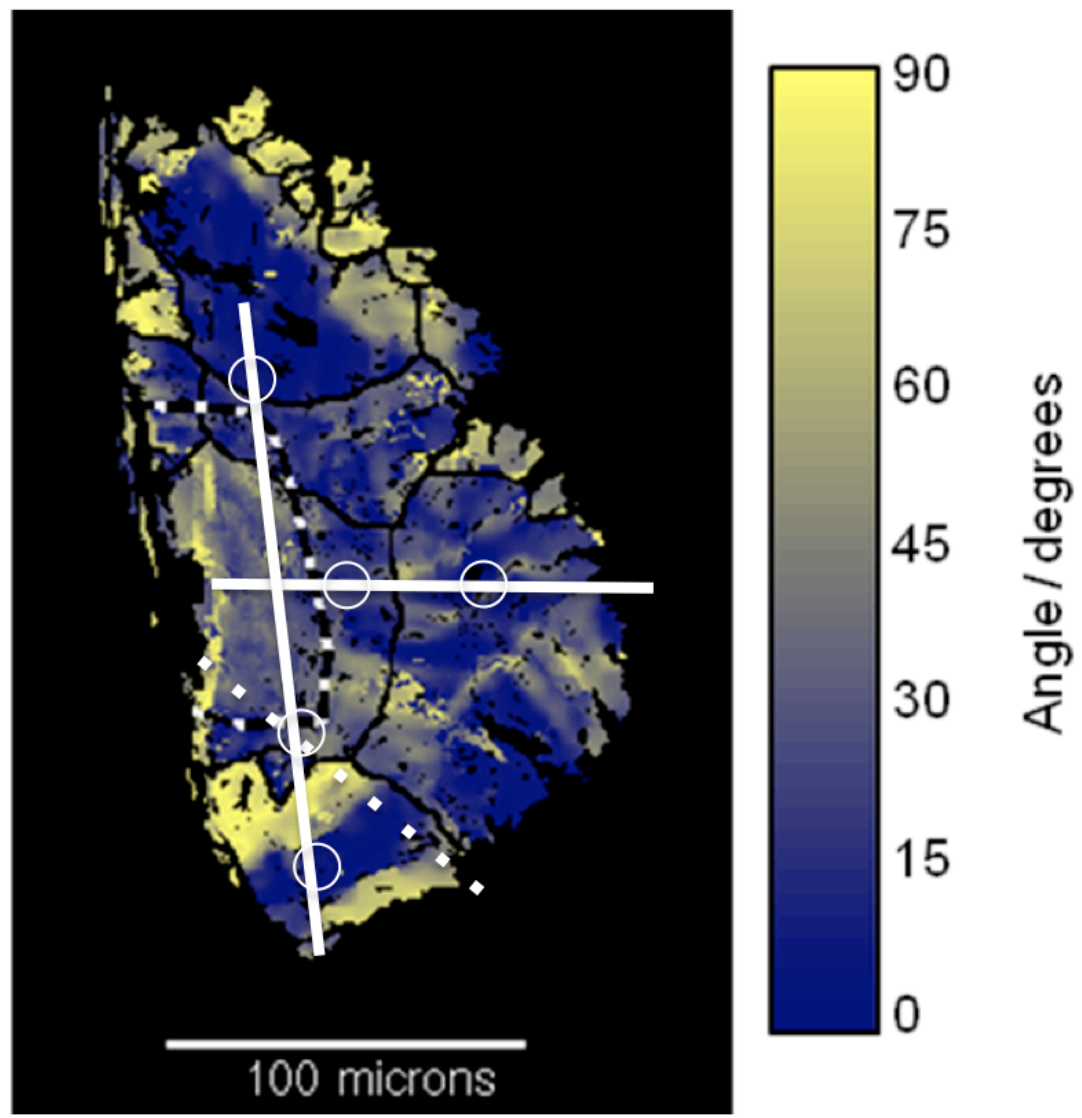

b)
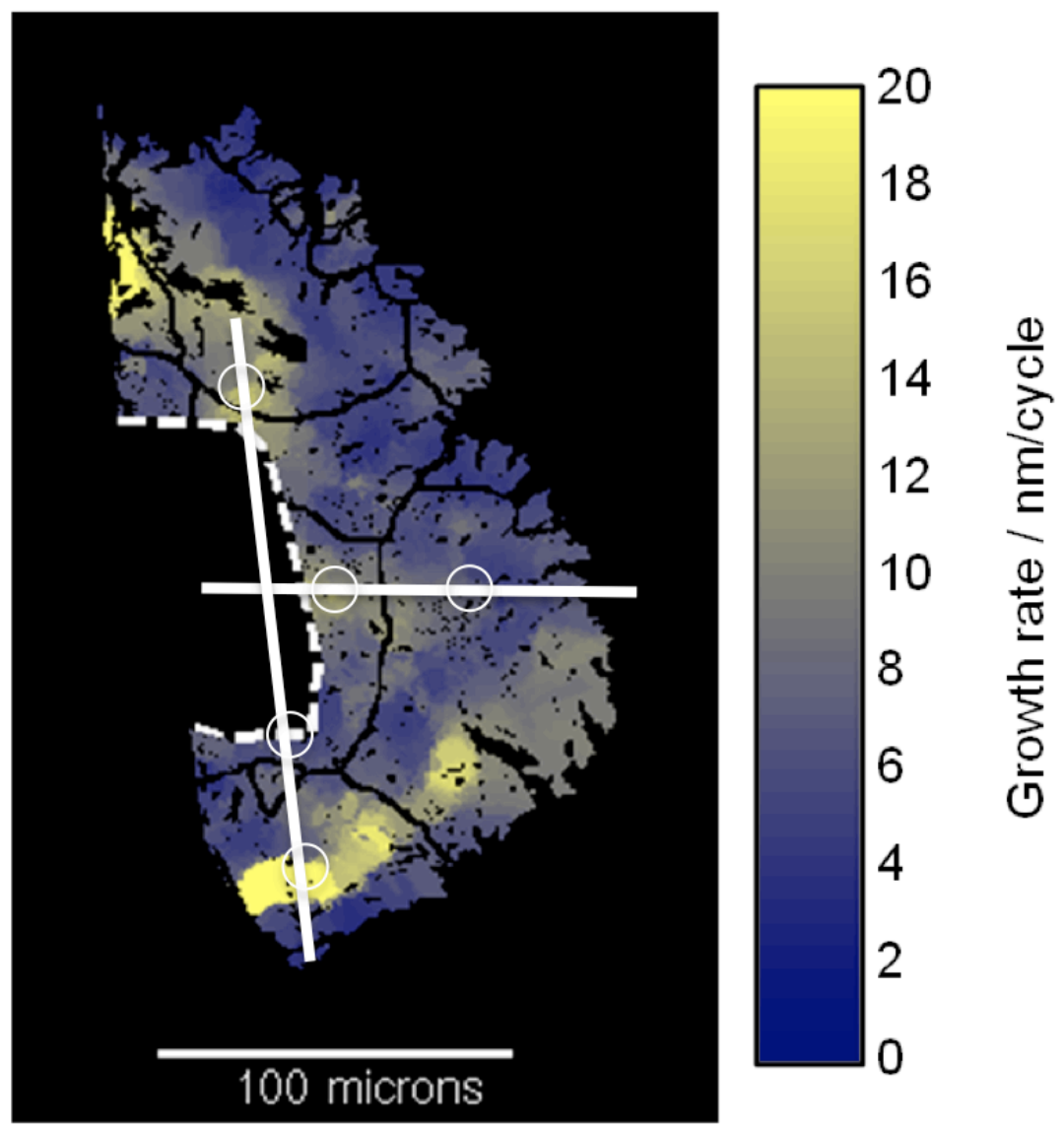

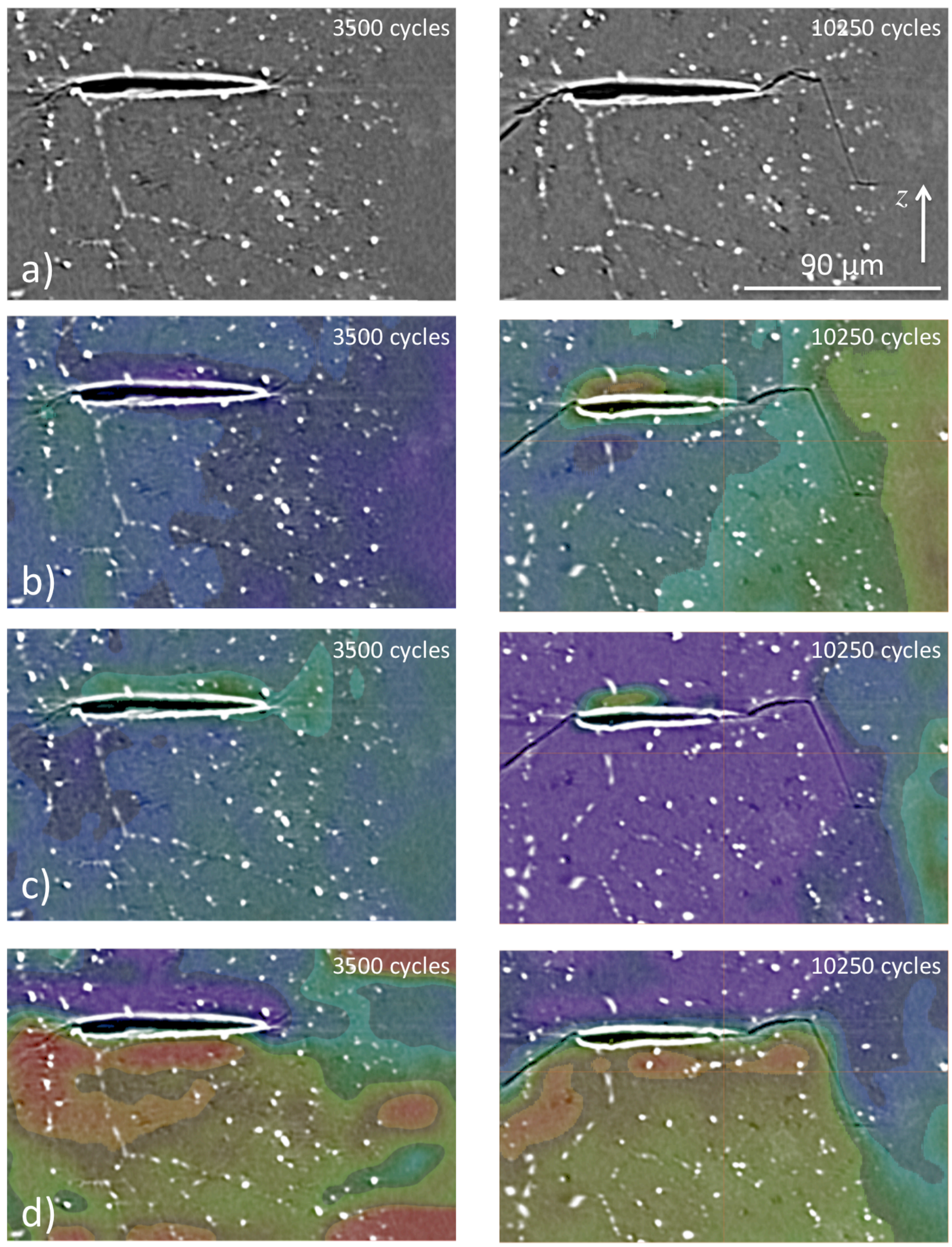

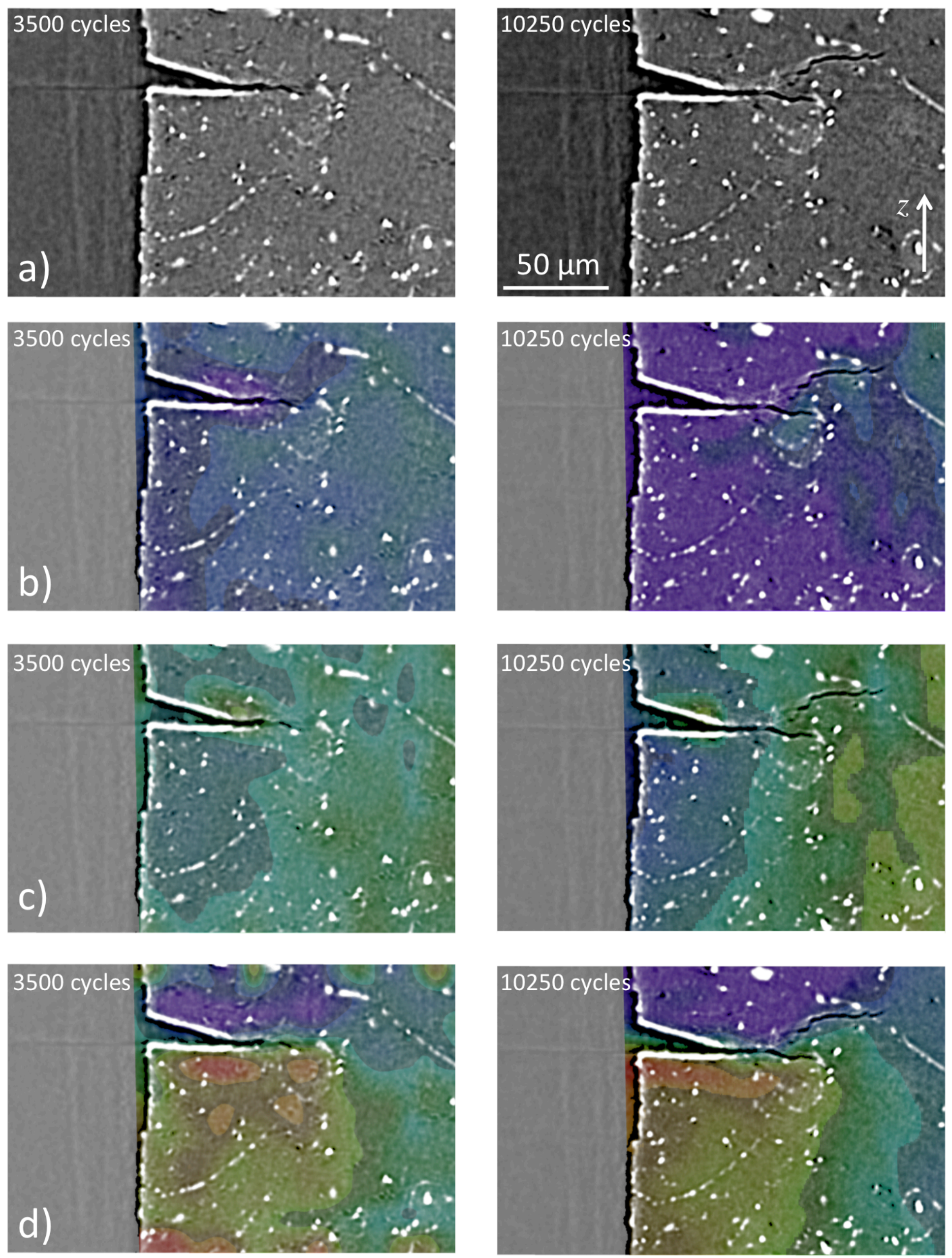

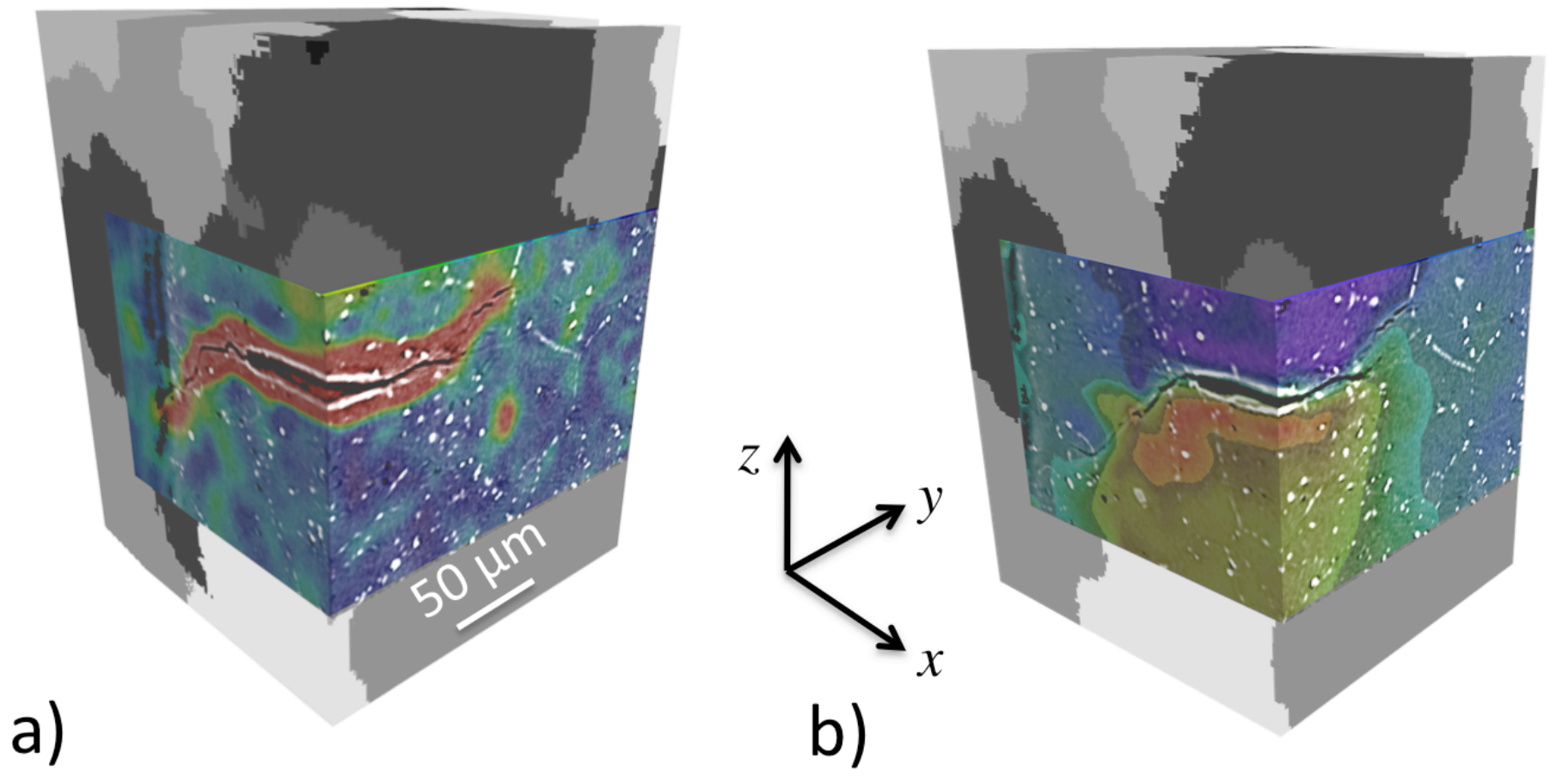


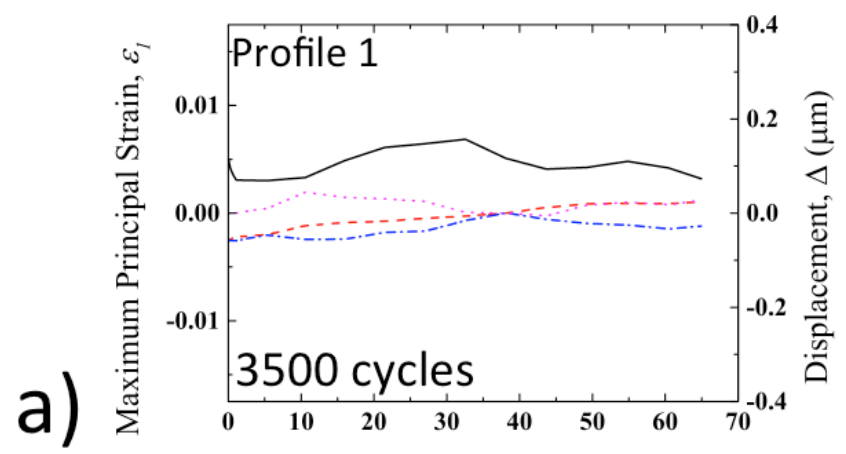

Distance along the profile, $\eta(\mu \mathrm{m})$

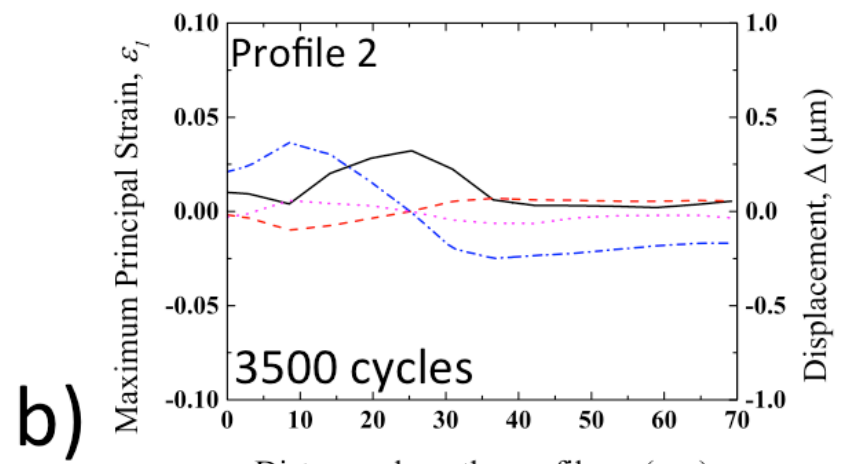

Distance along the profile, $\eta(\mu \mathrm{m})$
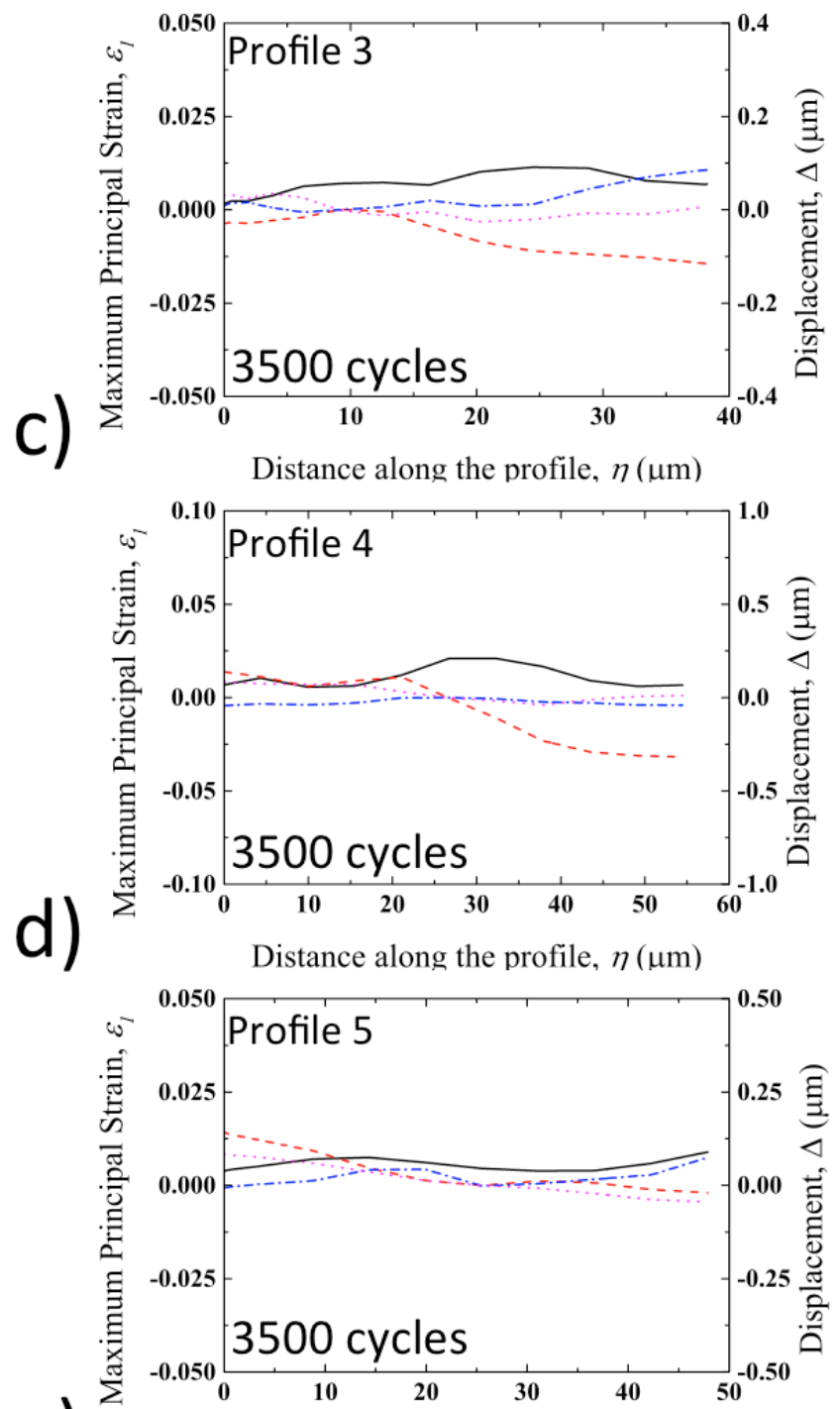

e) Distance along the profile, $\eta(\mu \mathrm{m})$

Maximum principal strain Opening displacement $\left(V_{\psi}\right)$

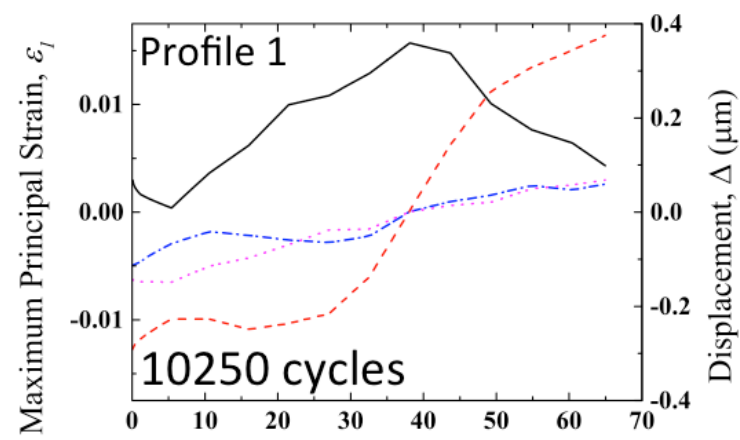

Distance along the profile, $\eta(\mu \mathrm{m})$

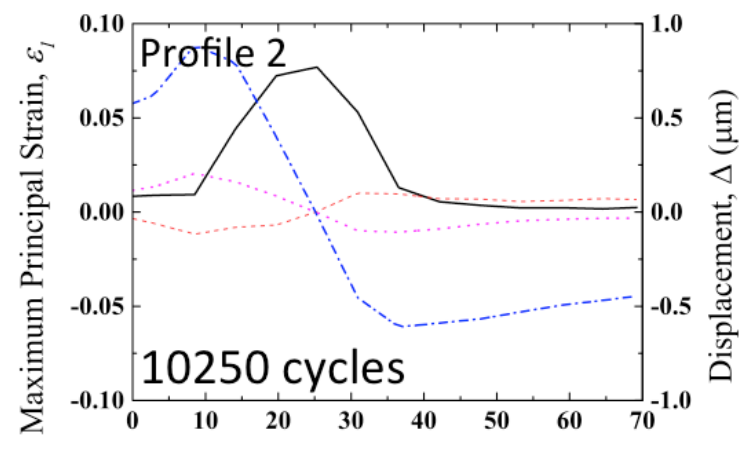

Distance along the profile, $\eta(\mu \mathrm{m})$

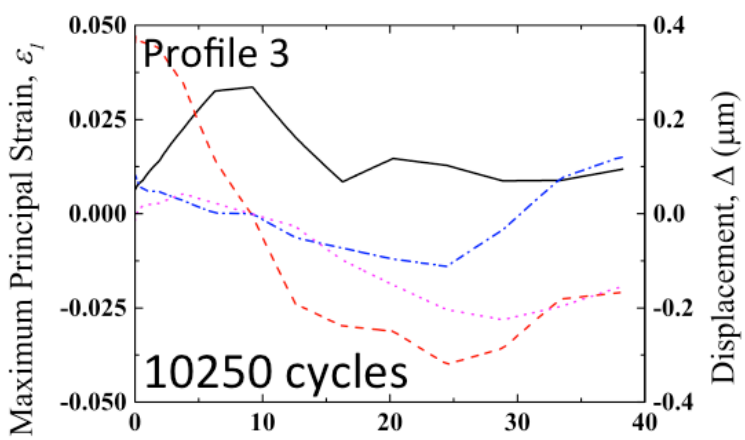

Distance along the profile, $\eta(\mu \mathrm{m})$
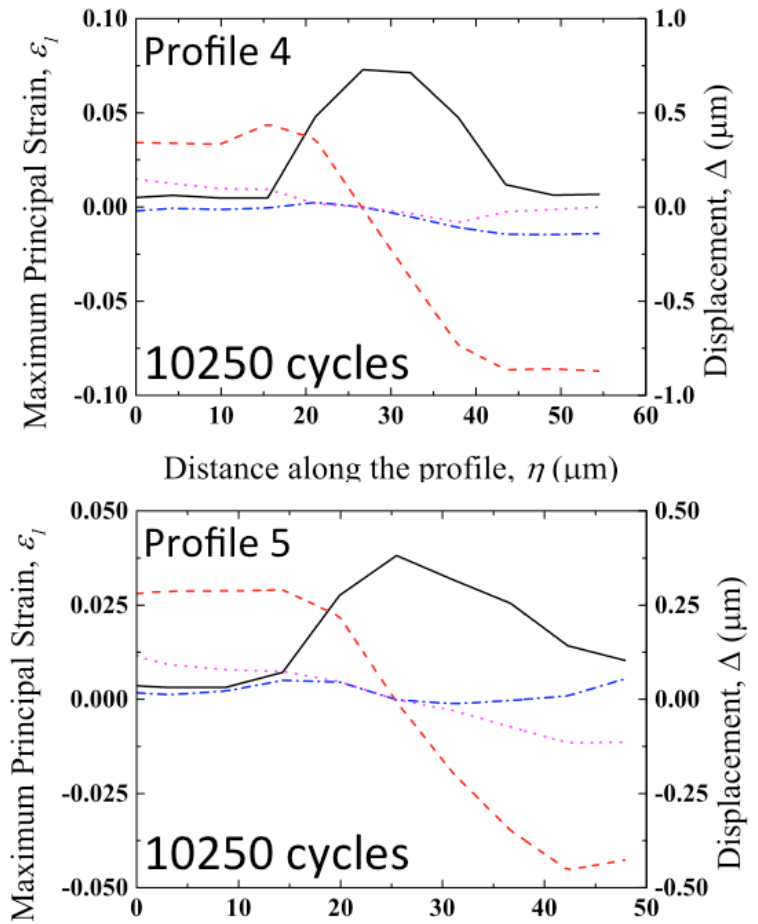

Distance along the profile, $\eta(\mu \mathrm{m})$

In-Plane shear displacement $\left(V_{\eta}\right)$

Out-of-plane shear displacement $\left(V_{\xi}\right)$ 